\title{
Histamine content of rectal mucosa in ulcerative colitis
}

\author{
VIBEKE BINDER AND EIGILL HVIDBERG \\ From Gentofte Hospital, Medical Department B, and \\ Medical Department F, Gentofte, Denmark
}

EDITORIAL COMMENT The histamine content of the rectal mucosa in ulcerative colitis correlates with the eosinophil content of the exudate, possibly the result of an allergic reaction.

Various investigations suggest an allergic pathogenesis of ulcerative colitis (Andresen, 1942; Truelove, 1961; Wright and Truelove, 1965; Rider, Moeller, Devereaux, and Wright, 1960; Taylor, Truelove, and Wright, 1964; Broberger and Perlmann, 1959). A considerable infiltration of eosinophils is seen in the mucosa of the rectum and colon as well as in the luminal inflammatory exudate (Truelove and Richards, 1956; Goldgraber, Kirsner, and Palmer, 1960; Anthonisen and Riis, 1962; Riis and Anthonisen, 1964). Histamine is assumed to play an important part in allergic reactions and it was therefore considered of interest to determine the histamine content of the mucosa in patients with ulcerative colitis. Three parameters have been compared: the mucosal histamine content, the distribution of different cell types in the rectal inflammatory exudate, and the clinical severity of the disease.

\section{METHODS}

CYTOLOGICAL TECHNIQUE Cytological examination of the rectal inflammatory exudate was performed according to the method of Anthonisen and Riis (1961). A proteincoated glass disc fixed on a cork was inserted through a sigmoidoscope and lightly pressed against the mucosa for about one second. The disc was dried in air and stained according to the May-Grünwald-Giemsa method. The number of cells was estimated semiquantitatively. In the present work eosinophilia indicates that more than approximately $20 \%$ of the cells in the total imprint were eosinophils. That corresponds to $\geqslant++$ eosinophils in the paper of Riis Valdorf-Hansen and Anthonisen (1966).

BIOPSY TECHNIQUE The biopsies were taken from various areas where immediately beforehand imprints for cytological examination had been made. A small biopsy forceps was used and suction was not employed. The forceps was introduced through a sigmoidoscope.
HISTAMINE DETERMINATION This was performed on dried defatted tissue specimens. Freeze drying was carried out until the weight was constant and defatting was performed using ethyl ether in which histamine is insoluble. Defatting reduced the dry weight by 0 to $10 \%$.

The dried defatted tissue specimen was homogenized in 3 or $5 \mathrm{ml}$. of $0.4 \mathrm{~N}$ perchloric acid depending upon the size of the specimen. After centrifugation all histamine was found in the supernatant. The analysis was performed according to the method of Shore, Burkhalter, and Cohn (1959). This procedure, which has also been used by Zachariae (1965), is based upon the fact that histamine reacts with orthophthalic acid forming a highly fluorescent compound with a characteristic spectrum (excitation $355 \mathrm{~nm}$, emission $445 \mathrm{~nm}$ ). An Aminco-Bowman spectrophotofluorometer was used. On account of the small size of the tissue samples double determinations were only carried out on 20 specimens. The mean difference was 3.6 $\mu$ g. (S.D. 3.6). The results are given as micrograms of histamine base per gram dried defatted tissue.

MATERIAL Seventy-eight biopsy specimens from 63 patients and controls were examined as shown in Table I. Fourteen of the 27 controls suffered from irritable colon and 13 presented no colonic symptoms at all. The diagnosis of irritable colon was based on typical symptoms combined with a good general condition, a normal appearance of the rectum, a cell-free imprint of the rectal mucosa, and absence of organic changes by radiological examination of the colon.

\section{TABLE I}

COMPOSITION OF CLINICAL MATERIAL AND NUMBER OF BIOPSY SPECIMENS

\begin{tabular}{|c|c|c|c|}
\hline Subjects & No. & $\begin{array}{l}\text { Average Age } \\
\text { (yr.) }\end{array}$ & $\begin{array}{l}\text { No. of Biopsy } \\
\text { Specimens }\end{array}$ \\
\hline Controls & $\begin{array}{rrr}27 & 0 & 11 \\
& 0 & 116\end{array}$ & $54 \cdot 7$ & 32 \\
\hline Ulcerative colitis & $\begin{array}{lr}36 & 014 \\
& 14 \\
& 22\end{array}$ & $41 \cdot 7$ & 46 \\
\hline
\end{tabular}


Thirty-six patients suffered from ulcerative colitis. The diagnosis was based on a typical history, sigmoidoscopy, cytological examination of the rectal inflammatory exudate, and radiological examination of the colon. In all cases the cytological examination at the time when the biopsy was taken showed signs of active inflammation, and in all patients sigmoidoscopy and radiological examination had shown typical changes, either at the time of the biopsy or previously.

The patients with ulcerative colitis have been classified into three groups according to the severity of the disease by evaluating the symptoms, the macroscopic appearance of the rectal mucosa, and cytological examination of the rectal inflammatory exudate.

Group 1: inactive No symptoms, i.e., not more than two bowel, movements daily, no admixture of blood, and no tenesmi or other intestinal complaints. No macroscopic changes of the rectal mucosa and not more than a few clusters of inflammatory cells in the rectal exudate.

Group 2: moderately active Mucus and blood in the faeces and occasional diarrhoea. The patient looks well. The rectal mucosa usually presents granulation and increased vulnerability. The rectal exudate contains many clusters of inflammatory cells.

Group 3: very active Frequent bloody diarrhoea. The patient looks ill. Pronounced granulation and vulnerability of the mucosa and sometimes ulcerations and pseudo-polyps. The rectal exudate contains numerous inflammatory cells.

\section{RESULTS}

The weight of the biopsy specimens averaged $21 \cdot 5$ mg. ranging from about 10 to about $50 \mathrm{mg}$. Two to five minutes elapsed from the moment when the biopsy was taken until the weighing took place. No correlation was demonstrated between the weight of the biopsy and the histamine content per weight unit.

Microscopy of the first six biopsies showed in all cases rectal mucosa. The muscularis mucosae had been touched tangentially, and submucosal tissue was not seen.

In five normal subjects biopsies were taken from two different areas in the rectum. The histamine concentration in these pairs of biopsies was almost identical (Table II).

\section{TABLE II}

HISTAMINE CONTENT OF DUPLICATE BIOPSY SPECIMENS FROM FIVE NORMAL SUBJECTS

\begin{tabular}{lcc} 
Subjects & $\begin{array}{c}\text { Histamine Base } \\
(\mu \mathrm{g} . / \mathrm{g} . \text { d.d.t. })(7 \mathrm{~cm} .)\end{array}$ & $\begin{array}{c}\text { Histamine Base } \\
(\mu \mathrm{g} . / \mathrm{g} . \text { d.d.t. })(12 \mathrm{~cm} .)\end{array}$ \\
\hline F.A. & $136 \cdot 0$ & $122 \cdot 0$ \\
A.E. & 34.9 & $30 \cdot 2$ \\
A.C. & 54.9 & $61 \cdot 6$ \\
C.R. & $55 \cdot 3$ & $58 \cdot 2$ \\
C.P. & $57 \cdot 2$ & $77 \cdot 5$ \\
d.d.t. $=$ dried, defatted tissue &
\end{tabular}

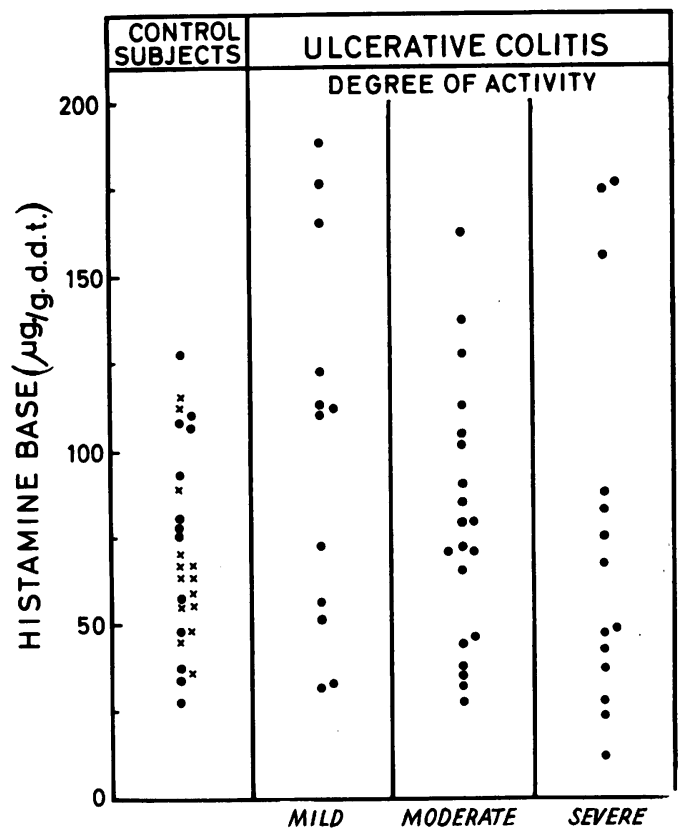

FIG 1. Histamine content in 27 biopsy specimens from 27 control subjects and in 46 biopsy specimens from 36 patients with ulcerative colitis classified according to severity.

$\times=$ Irritable colon; $O=$ no colonic symptoms; d.d.t. $=$ dried defatted tissue.

Mean values: Control subjects: no cells, 71.4. Ulcerative colitis: mild, $102 \cdot 9$; moderate, $9 \cdot 71$; severe, $76 \cdot 0$.

Standard deviations: Control subjects: no cells, 27.8 . Ulcerative colitis: mild, 55.1; moderate, 37.2: severe, $55 \cdot 3$.

Figure 1 shows the histamine content of the rectal mucosa in the control group. It averaged $67.0 \mu \mathrm{g}$. in persons suffering from irritable colon and $76.1 \mu \mathrm{g}$. in persons without colonic symptoms. These values do not differ significantly. No correlation was demonstrated between the histamine content and the age and sex of the control subjects.

Figure 1 also shows the histamine values found in the ulcerative colitis group classified according to the severity of the disease. No statistically significant difference was demonstrated between the histamine values in the three groups, although an increased degree of severity tended to be accompanied by decreased histamine values. A regression analysis showed no correlation between the histamine value as the dependent variable and the age of the patients and the duration of the disease as independent variables. The lack of correlation between age and histamine content in this material shows that the age difference between the two groups does not present a source of error. 


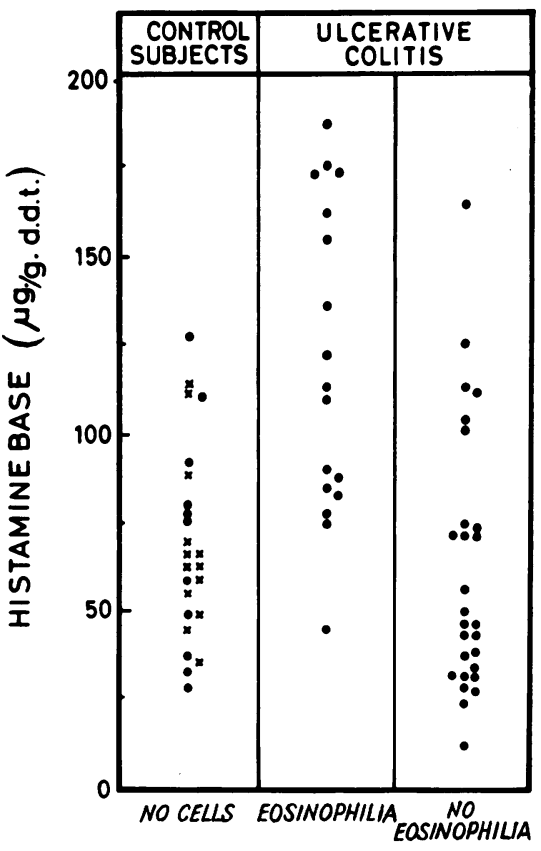

FIG. 2. Histamine content in 46 biopsy specimens from 36 patients with ulcerative colitis classified according to the presence of eosinophils in the inflammatory exudate. $\times=$ Irritable colon; $0=$ no colonic symptoms; d.d.t. = dried defatted tissue. Mean values: Control subjects: no cells $7 \cdot 14$. Ulcerative colitis: eosinophilia, $121 \cdot 7$; no eosinophilia, $52 \cdot 5$.

Standard deviations: Control subjects: no cells, 27.8. Ulcerative colitis: eosinophilia, 40.9; no eosinophilia, $36 \cdot 1$.

Figure 2 shows the histamine values in the ulcerative colitis group in relation to the presence of eosinophilia in the rectal exudate. In patients presenting eosinophilia in the exudate the histamine content averaged $121.7 \mu \mathrm{g}$. per g. dried defatted tissue, whereas the histamine content averaged $62.5 \mu \mathrm{g}$. in the patients not presenting eosinophilia in the exudate. This difference is statistically significant $(p<0.001)$. No significant difference, however, was demonstrated between the histamine values found in the control group and the values found in the ulcerative colitis patients not presenting eosinophilia in the exudate.

In Fig. 3 the ulcerative colitis group has again been classified according to the presence of eosinophilia in the rectal exudate and also according to the treatment given at the time of the investigation. In a few cases the histamine concentration was determined before and during treatment with sulphasalazine, but only changes which could be correlated with the cytological picture were demonstrated.
The water content of the biopsies varied considerably. In Fig. 4 the water concentrations of all biopsies in the patient group as well as the control group have been plotted against the histamine values. In the patient group high histamine concentrations tend to be accompanied by high water concentration, but the correlation is not statistically significant.

\section{DISCUSSION}

A highly significant correlation has been established in patients with ulcerative colitis between a high histamine content and relative eosinophilia of the rectal inflammatory exudate. The high histamine content was found in inactive cases with few cells in the rectal exudate as well as in active cases with numerous cells in the exudate, when only the eosinophils comprised more than $20 \%$ of the total number of cells. It is therefore reasonable to assume that it was not the total number of eosinophils which determined the histamine concentration in the tissue. The relationship has not been fully elucidated, but it appears from the results that a pronounced eosinophilia in the exudate, with one exception, was related to a histamine content which was greater than the average histamine content in the control group. Usually this average was exceeded by more than one standard deviation. Rectal exudates without eosinophilia were for the greater part related to histamine values below the average found in the control group but a few high values were observed.

It may be suggested that a high histamine content and a high percentage of eosinophils in the exudate are manifestations of a particular type of inflammatory reaction in the tissue, probably an allergic reaction. In this material such signs of an allergic reaction were found in one third of the cases of ulcerative colitis, bearing no relation to the severity of the disease. In patients treated with steroids allergic reactions are suppressed and in such patients eosinophilia in the exudate was absent and the histamine content was low.

The greater part of the histamine in the body is found in the mast cell granules (Riley and West, 1953). The number of mast cells in the rectal mucosa in normal subjects is small (Norris, Zamcheck, and Gottlieb, 1963) compared with other parts of the gastrointestinal tract. McAuley and Sommers (1961) observed an increased number of mast cells in the rectal lamina propria in 10 out of 25 cases of ulcerative colitis compared with that in one out of 25 controls.

Blood basophils also contain histamine although to a lesser degree. In this examination no basophils were seen in any of the rectal inflammatory exudates.

Archer (1963), Litt (1964a and b), Speirs (1958), 
and Zachariae (1965) have studied the relationship between histamine, eosinophils, and the allergic reaction, and diverging opinions have been presented as to the nature of this relationship. A direct proportionality between the histamine content and the number of eosinophils, as postulated by Litt (1964a), could not be confirmed in the present investigation.

Previous investigations of the histamine content of the rectal mucosa are to the knowledge of the authors not available. Stone, Merrill, and Meneely (1955) found that the duodenal and gastric mucosa in normal subjects contained about $14 \mu \mathrm{g}$. of histamine per gram fresh tissue or, assuming a water content of 70 to $80 \%, 50$ to $60 \mu \mathrm{g}$. of histamine per gram dried tissue. This value is of the same order of magnitude as the average value in the present control material. Such an agreement was, however, not to be expected, since Norris et al. found a great number of mast cells, particularly in the duodenal and gastric mucosa.

The close agreement between the histamine content of biopsies taken from different areas of the rectum in the same patient shows that single determinations of the histamine content may be considered representative of the whole rectal mucosa.

It appears from the range of the histamine content in the control group that it is subject to considerable individual variation.

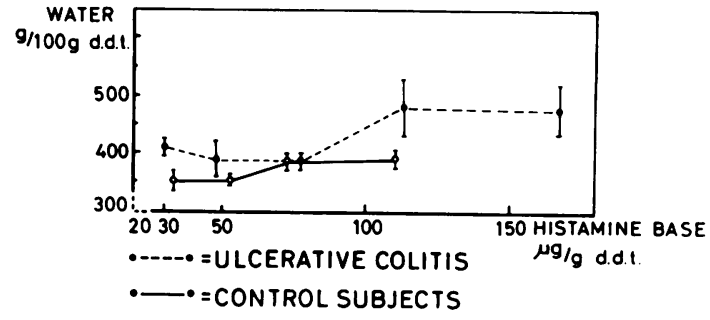

FIG. 4. Relation between water content and histamine content of biopsy specimens from patients with ulcerative colitis and from control subjects. Vertical lines indicate standard error of the mean.

$X=$ irritable colon $O=$ no colonic symptoms M.V. = mean value S.D. = standard deviation d.d.t. = dried, defatted tissue.

It must be noted that the estimated histamine concentration does not necessarily express the histamine activity, since an increased histamine turnover, as shown by Kahlson and Rosengren (1965), is not necessarily reflected by an increased tissue concentration. The histamine activity may be expressed by the 'histamine-forming capacity'.

In the present investigation the calculation of the histamine concentration was based on the weight of

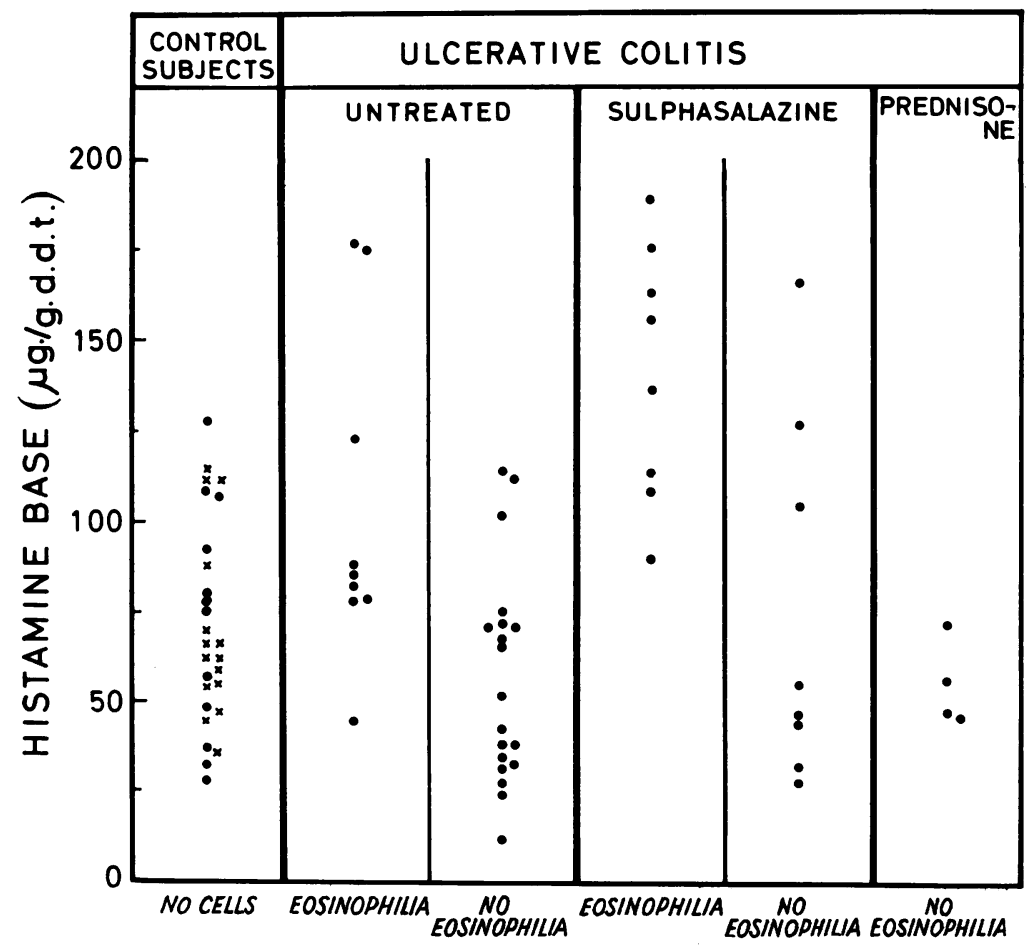

FIG. 3. Histamine content in 46 biopsy specimens from 36 patients with ulcerative colitis classified according to the treatment at the time of the biopsy and according to the presence of eosinophils in the inflammatory exudate. (Two patients treated with both sulphasalazine and prednisone are placed in both groups.) $\times=$ Irritable colon; 0 no colonic symptoms; d.d.t. $=$ dried defatted tissue.

Mean values: Control subjects: no cells, 71.4. Untreated colitis: eosinophilia, 103.9; no eosinophilia, 57.5. Sulphasalazine: eosinophilia, $141 \cdot 7$; no eosinophilia, 75.9. Prednisone: no eosinophilia, 56.0.

Standard deviations: Control subjects: no cells, 27.8. Untreated colitis: eosinophilia, 45.4; no eosinophilia, $30 \cdot 1$. Sulphasalazine: eosinophilia, $35 \cdot 0$; no eosinophilia, 50.4. Prednisone: no eosinophilia, 11.0. 
the dried defatted specimen, since this weight is independent of varying evaporation from the time of the biopsy until the weighing takes place. A source of error, however, remains since the biopsies had different water contents due to a variable degree of oedema. The oedema fluid, being a bulk filtrate of plasma, contains up to 7 or $8 \%$ of fat-free solids (Szporny, Langgård, and Hvidberg, 1964) and the weight of an oedematous mucosal biopsy will, therefore, even after drying and defatting, be greater than the weight of a corresponding non-oedematous biopsy. The histamine content of plasma is negligible, and the estimate of the histamine concentration in an oedematous biopsy will therefore be too small.

In cases of very active ulcerative colitis the mucosa is highly oedematous which may explain the uncertain negative correlation between the degree of severity of the disease and histamine content (Fig. 1). This objection to the calculation of the histamine content does not affect the correlation between eosinophilia in the exudate and a high histamine concentration. On the contrary the estimated histamine values may have been too small.

Variations in the state of hydration might explain the considerable individual variation in the histamine content found in the control group. It would have been ideal to calculate the histamine concentration against a constant parameter. Langgård (1965) proposes a unit of surface area of the mucosa for this purpose, but that is only practicable in animal experiments.

\section{SUMMARY}

The histamine content was determined in 46 biopsies of the rectal mucosa from 36 patients suffering from ulcerative colitis, and in 32 similar biopsies from 27 control subjects.

No certain correlation was established between the histamine content and the degree of severity or the duration of the disease. The histamine content was significantly increased in 17 cases, which presented pronounced eosinophilia in the rectal inflammatory exudate. In the rest of the patients the histamine values did not differ from those in the control group. It is assumed that the high histamine content as well as the high percentage of the eosino- phils in the rectal exudate are reflections of an allergic reaction in the mucosa.

\section{REFERENCES}

Andresen, A. F. R. (1942). Ulcerative colitis: an allergic phenomenon Amer. J. dig. Dis., 9, 91-98.

Anthonisen, P., and Riis, P. (1961). A new diagnostic approach to mucosal inflammation in prostocolitis. Lancet, 2, 81-82.

,$--(1962)$. The cytology of colonic secretion in proctosigmoidal disease. Acta med. scand., 172, 375-381.

Archer, R. K. (1963). The Eosinophil Leucocytes, chapter 7. Blackwell, Oxford.

Broberger, O., and Perlmann, P. (1959). Autoantibodies in human ulcerative colitis. J. exp. Med., 110, 657-674.

Goldgraber, M. B., Kirsner, J. B., and Palmer, W. L. (1960). The histopathology of chronic ulcerative colitis and its pathogenic implications. Gastroenterology, 38, 596-604.

Kahlson, G., and Rosengren, E. (1965). Histamine. Ann. Rev. Pharmacol., 5, 305-320.

Langgård, H. (1965). Bindevavets Elektrolytforhold, chapter 5. Borgen, Copenhagen.

Litt, M. (1964a). Eosincphils and antigen-antibody reactions. Ann. N.Y. Acad. Sci., 116, 964-985.

- (1964b). Studies in experimental eosinophilia. VI. Uptake of immune complexes by eosinopolis. J. Cell Biol., 23, 355-361.

McAuley, R. L., and Sommers, S. C. (1961). Mast cells in nonspecific ulcerative colitis. Amer. J. dig. Dis., 6, 233-236.

Norris, H. T., Zamcheck, N., and Gottlieb, L. S. (1963). The presence and distribution of mast cells in the human gastrointestinal tract at autopsy. Gastroenterology, 44, 448-455.

Rider, J. A., Moeller, H. C., Devereaux, R. G., and Wright, R. R. (1960). The use of an intramucosal test to demonstrate food hypersensitivity in ulcerative colitis. Acta allerg. (Kbh.), 15, suppl. 7, 486-494.

Riis, P., and Anthonisen, P. (1964). Eosinophilia in peripheral blood and inflammatory exudate in non-specific proctocolitis. Acta med. scand., 175, 85-89.

—, Valdorf-Hansen, F., and Anthonisen, P. (1966). Cytology of colonic mucosal secretions from patients with non-specific haemorrhagic proctocolitis in complete clinical remission. Brit. med. J., 1, 712-714.

Riley, J. F. and West, G. B. (1953). The presence of histamine in tissue mast cells. J. Physiol. (Lond.), 120, 528-537.

Shore, P. A., Burkhalter, A., and Cohn, V. H., Jr. (1959). A method for the fluorometric assay of histamine in tissues. J. Pharmacol. exp. Ther., 127, 182-186.

Speirs, R. S. (1958). Advances in the knowledge of the eosinophil in relation to antibody formation. Ann. N.Y. Acad. Sci., 73, 283-306.

Stone, J. L., Merrill, J. M., and Meneely, G. R. (1955). Distribution of histamine in human tissues. (Abstr.) Fed. Proc., 14, 147-148.

Szporny, L., Langgård, H., and Hvidberg, E. (1964). Quantitative investigations on the composition of acute inflammatory edema. Acta rheum. scand., 10, 196-208.

Taylor, K. B., Truelove, S. C., and Wright, R. (1964). Serologic reactions to gluten and cows milk proteins in gastrointestinal disease. Gastroenterology, 46, 99-108.

Truelove, S. C. (1961). Ulcerative colitis provoked by milk. Brit. med. J., 1, 154-166.

-, and Richards, W. C. D. (1956). Biopsy studies in ulcerative colitis. Ibid., 1, 1315-1318.

Wright, R. and Truelove, S. C. (1965). A controlled therapeutic trial of various diets in ulcerative colitis. Ibid., 2, 138-141.

Zachariae, H. (1965). Skin Histamine, chapter 4. Munksgaard. Copenhagen. 